\title{
The Sigma-2 Receptor/TMEM97, PGRMC1, and LDL Receptor complex are responsible for the cellular uptake of $A \beta 42$ and its protein aggregates
}

Aladdin Riad, ${ }^{1}$ Zsofia Lengyel-Zhand, ${ }^{1}$ Chenbo Zeng, ${ }^{1}$ Chi-Chang Weng, ${ }^{1}$ Virginia M.-Y. Lee, ${ }^{2}$ and John Q. Trojanowski ${ }^{2}$ and Robert H. Mach ${ }^{1^{*}}$

${ }^{1}$ Department of Radiology, University of Pennsylvania, Philadelphia, PA, USA, and ${ }^{2}$ Center for Neurodegenerative Disease Research, Pathology and Laboratory Medicine, University of Pennsylvania, Philadelphia, PA, USA

Author email addresses:

Aladdin Riad - Aladdin.Riad@pennmedicine.upenn.edu

Zsofia Lengyel-Zhand - Zsofia.Lengyel@pennmedicine.upenn.edu

Chenbo Zeng - zengc@pennmedicine.upenn.edu

Chi-Chang Weng - ccweng@mail.cgu.edu.tw

Virginia M.-Y. Lee-vmylee@upenn.edu

John Q. Trojanowski - trojanow@upenn.edu

Robert H. Mach - rmach@pennmedicine.upenn.edu

Number of Figures: 5

Supplementary Figures: 3

Key words: Amyloid Beta, Alzheimer's Disease, Sigma 2 Receptor, apolipoproteins, Neurons

${ }^{*}$ Corresponding Author:

Robert H. Mach, PhD

Department of Radiology

University of Pennsylvania

Vagelos Laboratories, 1012

231 S. 34th Street

Philadelphia, PA 19104-6323

phone: 215-746-8233

email: rmach@pennmedicine.upenn.edu 


\section{ABSTRACT}

Background: Our lab has recently shown that the Sigma-2 Receptor/Transmembrane Protein 97 (TMEM97) and Progesterone Receptor Membrane Component 1 (PGRMC1) form a complex with the Low Density Lipoprotein Receptor (LDLR), and this intact complex is required for efficient uptake of lipoproteins such as LDL and apolipoprotein E (apoE). These receptors are expressed in the nervous system where they have implications in neurodegenerative diseases such as Alzheimer's Disease (AD), where apoE is involved in neuronal uptake and accumulation of $A \beta 42$, eventually cascading into neurodegeneration, synaptic dysfunction, and ultimately, dementia.

Hypothesis: We hypothesize that the intact Sigma-2 receptor complex -TMEM97, PGRMC1, and LDLR - is necessary for internalization of apoE and A 342 monomers (mAß42) and oligomers (oA 342 ), and the disruption of the receptor complex inhibits uptake.

Results: The results of this study suggest that the intact Sigma-2 receptor complex is a binding site for $\mathrm{mA} 442$ and $\mathrm{oA} \beta 42$, in the presence or absence of apoE2, apoE3, and apoE4. The loss or pharmacological inhibition of one or both of these proteins results in the disruption of the complex leading to decreased uptake of $\mathrm{mA} \beta 42$ and $\mathrm{oA} \beta 42$ and apoE in primary neurons.

Conclusion: The TMEM97, PGRMC1, and LDLR complex is a pathway for the cellular uptake of Aß42 via apoE dependent and independent mechanisms. This study suggests that the complex may potentially be a novel pharmacological target to decrease neuronal $A \beta 42$ internalization and accumulation, which may represent a new strategy for inhibiting the rate of neurotoxicity, neurodegeneration, and progression of $A D$. 


\section{INTRODUCTION}

The sigma receptors are a family of receptors who are poorly characterized. They were initially thought to be a subset of the opioid receptor family, but were later identified to be a distinct subset of receptors that include the Sigma-1 and Sigma-2 receptors [1-4]. The Sigma-2 receptor is expressed highly in proliferating cancer tumor cells and has been an attractive target for imaging solid tumors [2]. The Sigma2 receptor has also been used as a target for the treatment of central nervous system (CNS) disorders such as depression and psychosis [5] , and it has been recently studied as a potential pharmacological target for treating Alzheimer's Disease $(A D)[6,7]$.

Our previous work has shown that Sigma-2 Receptor/Transmembrane Protein 97 (TMEM97) and Progesterone Receptor Membrane Component 1 (PGRMC1) form a complex with the Low Density Lipoprotein Receptor (LDLR) [8], and this intact complex is important for the efficient uptake of low density lipoprotein (LDL). We found that disrupting this complex by genetically ablating or by pharmacologically targeting TMEM97 or PGRMC1 resulted in a decreased capacity for LDL internalization. For this reason, we choose to study the role of this complex in the internalization of Amyloid Beta 1-42 (Aß42) and apolipoprotein E (apoE).

A 342 is a peptide formed from the cleavage of amyloid precursor protein (APP) [9-11]. The accumulation of $A \beta 42$ in the brain results in aggregation into neurotoxic oligomers and fibrils [12] leading to deposition into amyloid plaques, the hallmark of a brain afflicted by AD [13]. Although amyloid beta plaques are extracellular, mounting evidence suggests that aggregation also begins within neurons, where uptake and subsequent degradation within lysosomes has been dysregulated leading to intraneuronal accumulation leading to aggregation [14-20]. Recent evidence suggests the cell-to-cell transfer of $A \beta 42$ also plays a role in the pathogenesis of $A D$ [20-25]. Reducing neuronal uptake may slow the cytotoxic effects of intracellular aggregation.

ApoE is a protein that mediates lipid homeostasis by facilitating transport of lipids within the various aqueous biological environment to cells and tissues within the body [26]. Within the CNS, apoE is primarily produced by astrocytes and transports cholesterol to neurons via its recognition by the LDLR family including LDLR and LDLR-related protein (LRP) receptors [27]. The main isoforms of apoE is apoE3, with apoE2 and apoE4 being the result of a single amino acid mutation. The presence of one apoE4 allele results in a 3-fold increased risk for developing $A D$, while the presence of two alleles result in a 12-fold 
increased risk factor, while patients with one or more apoE2 alleles have a reduced risk for developing $A D$ [28]. ApoE has been shown to interact with $A \beta 42$ and affect its clearance from the CNS, and increasing deposition into plaques [29].

In this study, we examined the role of the TMEM97/PGRMC1/LDLR protein complex in the uptake of $A \beta 42$ and its protein aggregates and apoE, separately and when in a complex with one another. Our studies assessed the role of uptake in a HeLa cell model system, and in a primary neuronal cell culture system. We provide experimental evidence for the importance of this intact complex for the uptake of $A \beta 42$ and apoE, and show that disrupting the complex pharmacologically results in decreased uptake, which alludes to the prospect that this complex being a therapeutic target for limiting the progression of AD. 


\section{RESULTS}

\section{The role of the TMEM97 and PGRMC1 in Aß42 and apoE uptake}

Samples of $A \beta 42$ monomers (mAß42), oligomers, (oA $\beta 42)$, and fibrils were prepared using previously published methods [30-32]. Transmission electron microscopy (TEM) images showed that $\mathrm{mA} \beta 42$ preparations contained no aggregated particles, oA 342 samples showed small, round particles with no protofibrils or fibrils present, and $\mathrm{f} A 342$ samples contained well defined filaments with no protofibrils or aggregated oligomers (SI Appendix, Fig. S1A). Dot blot analysis indicated positive reactivity for all samples with $A \beta 426 E 10$ antibody, which recognizes all species of $A \beta 42$, however only oA $\beta 42$ showed positive reactivity to the oligomer specific A11 antibody, indicating pure samples of the three aggregation states (SI Appendix, Fig. S1B).

Our previous work indicated that TMEM97 and PGRMC1 form a trimeric complex with the LDLR, and this complex is necessary for efficient uptake of LDL. As apoE can be taken up through the LDLR and is associated with $A \beta 42$, we sought to assess this complex's role in uptake of $A \beta 42$ and apoE3. To conduct these experiments we utilized four HeLa cell lines, control (Scramble/Cas9), TMEM97 KO, PGRMC1 KO, and TMEM97/PGRMC1 double KO (DKO). These cell lines were generated in our group utilizing CRISPR/Cas9 technology; previous studies characterized these cell lines and western blot data demonstrated a complete ablation of TMEM97 and/or PGRMC1 in the knockout cells [8, 33]. Cells were incubated in lipoprotein-depleted serum (LPDS) for 24 hours in order to induce expression of LDLR. Cells were treated with $1000 \mathrm{nM}$ mAß42, oA 42 , or $\mathrm{fA} \beta 42$ alone and in combination with $250 \mathrm{nM}$ apoE for 24 hours at $37^{\circ} \mathrm{C}$. Cell associated $\mathrm{A} \beta 42$ and apoE3 was quantified via ELISA (Fig. $1 \mathrm{~A}$ and B). The first observation of these experiments was mAß42 is more efficiently taken up by cells when it is in a complex with apoE3. Uptake of the mAß42/apoE3 complex was significantly decreased in the TMEM97 KO, PGRMC1 KO, and DKO cell lines when compared to Scramble/Cas9. Uptake of oA $\beta 42$, and to a lesser extent $\mathrm{f} A \beta 42$, alone and when in complex with apoE3 was also significantly decreased in the knockout cell lines. Uptake of apoE3 was also significantly less in the knockout cell lines compared to Scramble/Cas9 control cell (Fig. 1B). These results indicate that TMEM97 and PGRMC1 mediate internalization of Aß42 and apoE3, so our next goal was to evaluate the effect of pharmacological inhibition of TMEM97 and PGRMC1 on A 42 and apoE3 internalization in the Scramble/Cas9 cells. We utilized two TMEM97 ligands, 
RHM-4 (Kd $\sim 0.2 \mathrm{nM})$ and SW43 $(\mathrm{Kd} \sim 12 \mathrm{nM})$, and a PGRMC1 ligand AG-205 (Kd $\sim 1 \mu \mathrm{M}$ against Sigma2R

[8]). Scramble/Cas9 cells when treated with 500 nM RHM-4, SW43, or AG-205 showed significantly reduced capacity for internalizing $\mathrm{mA} \beta 42$ and $\mathrm{oA} \beta 42$ alone or when complexed with apoE3; and to a lesser extent reduced the cell associated fAß42 alone or when complexed with apoE3 (Fig. 1C). The compounds also resulted in significantly less uptake of apoE3 alone or when in a complex with any of the $A \beta 42$ aggregated states (Fig 1D).

To visualize uptake of $\mathrm{oA} \beta 42$, the control and knockout cell lines were treated with $3 \mu \mathrm{M}$ fluorescently labeled oA 342 for 10 minutes, 30 minutes, and 60 minutes. Cells were washed thoroughly then imaged immediately after addition of Hoechst to stain nuclei. Scramble/Cas 9 cells showed significantly more uptake of oligomers compared to the knockout cell lines at all time points since the internalized signal increased over time (Fig 2A). Interestingly fluorescent $\mathrm{fA} 42$ was not internalized by the cells, but accumulated on the cell surface (Fig 2B).

\section{TMEM97 and PGRMC1 primary rat cortical neurons}

The next goal of this study was to assess the ability of TMEM97 and PGRMC1 ligands to inhibit the uptake $A \beta 42$ in its various aggregation states and the apoE isoforms, apoE2, apoE3, and apoE4. Our first goal was to identify the presence of the trimeric complex in cultured primary neurons. For these studies we used mature DIV 21 primary rat cortical neurons, evident by their morphology and expression of MAP2 (Fig 3A). We identified the presence of the trimeric complex in a pairwise proximity ligation assay (Fig $3 \mathrm{C}$ ), as evident by the interaction of LDLR and PGRMC1, LDLR and TMEM97, and TMEM97 and PGRMC1. Taken together, these data indicate that the three proteins form a trimeric complex in primary neurons. Radiolabeled RHM-4 was able to bind with homogenates of primary rat neurons (Fig. 3 B), with an observed $\mathrm{Kd}$ of $1.37 \mathrm{nM}$ and a Bmax of $1448 \mathrm{fmol} / \mathrm{mg}$, further indicating the presence and high expression of TMEM97 in the primary neurons.

Primary neurons were treated with $\mathrm{mA} \beta 42$ in the presence or absence of apoE2, apoE3, and apoE4, for 24 hours. For each treatment, a no-compound-treated group was compared to cells treated with 500nM RHM-4, SW43, and AG-205. The amount of A 342 and apoE was quantified via ELISA (Fig. 4 A and D). Results indicate that pharmacological inhibition of TMEM97 and PGRMC1 results in a decrease in 
$\mathrm{mA} \beta 42$ and all apoE isoforms. There was an increase in uptake of $A \beta 42$ in complex with the various apoE isoforms in a rank order of apoE2 < apoE3 < apoE4; interestingly all compounds were able to inhibit the $m A \beta 42-A p o E$ complex with all three isoforms (E2, E4, E4), indicating potential therapeutic use in patients with any of the apoE alleles. The same trend was observed for oAß42 in the presence and absence of the apoE isoforms (Fig $4 \mathrm{~B}$ and $\mathrm{E}$ ). As expected from the previous observation that $\mathrm{f} A 342$ is not internalized but rather accumulates on the cell surface, $\mathrm{fA} \beta 42$ was not readily taken up by cultured neurons, and the compounds did not have an effect on cell associated $\mathrm{A} A 342$ alone or in a complex with apoE. Curiously, apoE was not inhibited by the TMEM97 or PGRMC1 ligands when in a complex with $\mathrm{fA} \beta 42$, which may be due to the fact that it accumulates on the surface along with $\mathrm{fA} 42$ and is not internalized. We observed that the internalized oA 42 was associated with MAP2 positive neurons (SI Appendix, Fig. S2).

The next step was to determine if the TMEM97/PGRMC1/LDLR trimeric complex is present in human brain tissue. In this study, samples of frontal cortex from postmortem cognitively normal subjects and a subject identified with $A D$ (Fig. 5) were used. The normal brain tissue section was from a patient with no clinical history of dementia or cognitive impairment, and the presence of neurofibrillary tangles was not observed in the pathology report. The AD brain section was from a patient with a clinical history of AD, with the pathology report indicating high level of amyloid beta, tau, and alpha-synuclein positive inclusions, along with numerous neurofibrillary tangles prominent in the frontal cortex. The AD tissue section displayed positive staining for $A \beta$ whereas the normal human tissue sections did not show a signal in immunofluorescent staining with an $A \beta$ antibody (SI Appendix, Fig. S3). We observed that the trimeric complex is intact in both human tissue samples, and signifies that our results in both the HeLa model system and primary cultured neuronsative of the conditions present in adult human brain. Consequently, our observations that pharmacologically targeting this complex blocks the uptake of $A \beta 42$ and ApoE-associated Ab42 may represent a novel strategy for preventing the cellular uptake and cell-to-cell transmission of beta amyloid peptide. 


\section{DISUCSSION}

In the current study, we provide strong experimental evidence that TMEM97 and PGRMC1 are therapeutic targets for inhibition of $A \beta 42$ and apoE uptake. Evidence suggests that increased uptake of these neurotoxic $A \beta 42$ peptides results in accumulation and aggregation within neurons eventually leading the formation of plaques and neuronal death $[34,35]$. Due to the apoE4 allele being greatest risk factor associated with development of AD, LDLR and the LRP family have been the focus of many studies [3638]. In our previous study, we described a trimeric protein complex formed between LDLR, TMEM97, and PGRMC1, and that this intact complex is important for efficient uptake of LDL in cancer cells. In the current study, we confirmed that the trimeric TMEM97/PGRMC1/LDLR complex is intact in primary rat cortical neurons (Fig. 3C) and in human brain tissues, both in non-diseased human brain and in AD brain samples

(Fig. 5). The goal of this study was to assess the importance of this intact complex, and its potential target for pharmacological intervention, on $A \beta 42$ and apoE-associated $A \beta 42$ uptake.

Knocking out TMEM97 and/or PGRMC1 in HeLa cells resulted in a marked decrease of mAß42 and oAß42 uptake alone or when in a complex with apoE. The uptake of mAß42 in HeLa cells was enhanced by the presence of apoE (Fig. $1 \mathrm{~A}$ and C), but interestingly this reliance on apoE as a chaperone for uptake was not observed in the primary cultured neurons (Fig. 4 A and D). Conversely, oAß42 did not require apoE to be taken up by HeLa cells (Fig. $1 \mathrm{~A}$ and C) or primary neurons (Fig. $4 \mathrm{~B}$ and E). These observations are consistent with previous reports [39]. In both the HeLa model system and primary neuronal cells, RHM-4, SW43, and AG-205 were able to reduce uptake of mAß42 and oAß42 alone and when in a complex with apoE. The results highlight the role of TMEM97 and PGRMC1 in neuronal Aß42 and apoEassociated AB42 uptake, and reinforces the therapeutic potential of the TMEM97-PGRMC1-LDLR trimeric complex as a target for reducing $A \beta 42$ accumulation in neurons.

The propagation of toxic aggregates throughout the $A D$ brain has spurred research on the neuronal transfer of $A \beta 42$. This cell-to-cell transfer was initially explored after the observation that the neuronal dysfunction that led to memory impairment also caused pathological changes in neighboring cells [25, 40]. There have been several proposed mechanisms by which this process occurs including exosomes and direct transmission of $A \beta 42$ from neuron to neuron that are directly connected by tunneling nanotubes [22]. Exosomes have been investigated as a means of neuron to neuron transfer of $A \beta 42$, as oA $A 42$ has been 
detected within neuronal exosomes. Data from cells treated with these exosomes also revealed that the exosomes facilitated delivery of oAß42 and induced toxic effects [24]. It is tempting to speculate that LDLR or LRP1 play a role in the uptake of these exosomes, thus implicating the TMEM97-PGRMC1-LDLR complex as a potential target in reducing the spread of cytotoxic aggregates. Further research delineating the role of TMEM97 and PGRMC1 in neuronal transfer of not only aggregated Aß42 species, but other aggregated protein such as alpha synuclein and tau, will be of great interest.

In conclusion, the results from this study reveal that TMEM97 and PGRMC1 may be novel therapeutic target for inhibiting neuronal uptake of $A \beta 42$ and $A p o E-a s s o c i a t e d ~ A \beta 42$ and potentially reduce $A \beta$-associated neurotoxicity. The modulation of intercellular and extracellular $A \beta 42$ pools may have a positive influence on clearance by keeping $A \beta 42$ in the extracellular space where it may be readily available for proteolytic degradation or clearance to the CSF. Developing compounds that target the TMEM97/PGRMC1/LDLR complex may represent a novel strategy in delaying the clinical progression of $A D$. Whether or not this mechanism has implications in other CNS disorders involving protein aggregates such as alpha-synuclein in Parkinson's Disease or the aggregation of tau in tauopathies is currently under investigation. 


\section{MATERIALS AND METHODS}

\section{Materials}

$N$-(4-(6,7-dimethoxy-3,4-dihydroisoquinolin-2(1H)-yl)butyl)-2,3-dimethoxy-5-iodo-benzamide and [125I]N(4-(6,7-dimethoxy-3,4-dihydroisoquinolin-2(1H)-yl)butyl)-2,3-dimethoxy-5-iodo-benzamide were synthesized as previously described [41, 42]. Hoechst 33342 (BD Pharmingen, 561908).

\section{Postmortem Human Brain Samples}

Human brain tissue samples from donor subjects following neuropathological evaluation were obtained from the brain bank at the Center for Neurodegenerative Disease Research at the University of Pennsylvania based on previously published criteria [43-45]. The methodology for brain harvest, selection of areas of interest, and diagnostic procedures and criteria have been previously reported.

\section{Cell Culture}

HeLa cell TMEM97 knockout, PGRMC1 knockout, and DKO cell lines were generated as previously described [8]. Cells were cultured in MEM with 10\% FBS, 1X penicillin/streptomycin, 2mM L-glutamine, and 1X MEM non-essential amino acids. For uptake experiments, cells were plated, and incubated for 24 hours, media was removed and cells were incubated in MEM containing 10\% lipoprotein depleted serum for an additional 24 hours prior to treatment.

\section{Primary Cortical Rat Neuron Cell Culture}

Primary neurons were acquired from University of Pennsylvania Neurons R Us and plated in poly-D-lysine coated 6 well plates at 400 cells/well or in poly-D-lysine coated 8 well chamber slides at 100 cells/well in Neurobasal Plus Media supplemented with B27 Plus, 1X GlutaMAX, and 0.5X penicillin/streptomycin. Media was partially exchanged every three days. Cells were cultured for 21 days prior to use in experiments.

\section{Aß42 fibril preparation}


A 442 fibril was prepared as described previously [32]. Briefly, monomeric A $\beta 42$ (Millipore-Sigma, A9810) was dissolved in hexafluoroisopropanol (HFIP) at a concentration of $2 \mathrm{mg} / \mathrm{mL}$ and incubated for 1 hour at $37{ }^{\circ} \mathrm{C}$ until the peptide completely dissolved. Then HFIP was evaporated under air. The peptide powder was dissolved again in HFIP $(2 \mathrm{mg} / \mathrm{mL})$, aliquoted $(50 \mu \mathrm{L})$ and left to dry overnight under vacuum. Aliquots were stored in a freezer at $-20^{\circ} \mathrm{C}$.

To prepare fibrils, the HFIP-treated peptide aliquot was dissolved in $10 \mathrm{mM} \mathrm{NaOH}(10 \mu \mathrm{L})$ solution, then the sample was diluted with $90 \mu \mathrm{L} 10 \mathrm{mM}$ phosphate buffer, $\mathrm{pH}$ 7.4. Concentration of the peptide solution was confirmed by measuring the absorbance at $214 \mathrm{~nm}$ with NanoDrop 2000c spectrophotometer. Extinction coefficient $\left(76848 \mathrm{M}^{-1} \mathrm{~cm}^{-1}\right)$ was calculated using literature values [30]. Next, the solution was agitated by a continuous slow rotation at room temperature for 3 days and fibril formation was confirmed by TEM.

Oligomers were prepared as previously described [31]. An aliquot of HFIP-treated peptide was dissolved in anhydrous DMSO $(5 \mu \mathrm{M})$ and diluted to $100 \mu \mathrm{M}$ in serum-free and phenol red-free cell culture media, followed by incubation at $4{ }^{\circ} \mathrm{C}$ for 24 hours.

Fluorescent $A \beta 42$ oligomers and fibrils were prepared similarly with HiLyte Fluor 555-labeled $A \beta 42$ (Anaspec, AS-60480-01) and mixed with non-labeled $A \beta 42$ peptides in a 1:2 ratio.

\section{Transmission electron microscopy}

Samples $(5 \mu \mathrm{L})$ were spotted onto glow-discharged formvar/carbon-coated, 200-mesh copper grids (Ted Pella). After $1 \mathrm{~min}$, grids were washed briefly with water and stained with one $10 \mu \mathrm{L}$ drop of $2 \% \mathrm{w} / \mathrm{v}$ uranyl acetate for $1 \mathrm{~min}$. The excess stain was removed by filter paper and the grids were dried under air. Samples were imaged with a Tecnai FEI T12 electron microscope at an acceleration voltage of $120 \mathrm{kV}$. Images were recorded on a Gatan OneView 4K Cmos camera.

\section{ApoE Preparation}

Recombinant apoE2 (Millipore-Sigma, SRP4760), apoE3 (Millipore-Sigma, SRP4696), and apoE4 (Abcam, ab50243) was reconstituted per manufacture instruction to a concentration of $1 \mathrm{mg} / \mathrm{mL}$, aliquoted, and 
stored at $-80^{\circ} \mathrm{C}$. Prior to use, apolipoprotein was lipidated with dimyristoyl- phosphatidylcholine (DMPC) (Millipore-Sigma, P2663) using a procedure adapted from [46]. Briefly, DMPC vesicles $(10 \mathrm{mg} / \mathrm{mL}$ in in PBS) were prepared by sonicating until solution was clear. These were mixed with apoE $(37.5 \mu \mathrm{L}$ vesicles to $100 \mu \mathrm{g}$ apoE) and the solution was cycled three times through the transition temperature of the DMPC $\left(23.5^{\circ} \mathrm{C}\right.$ ) by warming to $30^{\circ} \mathrm{C}$ for 30 minutes and cooling to $15^{\circ} \mathrm{C}$ for 30 minutes using a thermocycler. To form a complex with $A \beta 42$, the lipidated apoE solution was added immediately to $A \beta 42$ (at a molar ratio of $1: 4)$ and incubated at $37^{\circ} \mathrm{C}$ for 30 minutes.

\section{Dot blot analysis}

$2 \mu \mathrm{g}$ of $\mathrm{A} \beta 42$ monomers, oligomers, and fibrils were spotted on nitrocellulose membrane and allowed to dry for 1 hour at room temperature. Membranes were blocked with Odyssey blocking buffer (927-40100 Licor Biotechnology, Lincoln, NE) for 1 hour at room temperature, then incubated with primary antibody (A11 1:10000) (Invitrogen, AHB0052) or 6E10 (1:1000) (Biolegend, 803001) overnight at $4^{\circ} \mathrm{C}$. Membranes were washed 3 times with PBS-T (0.2\% Tween-20) for 5 minutes, then incubated with secondary antibody secondary antibody, IRDye 680CW anti-rabbit IgG (Licor Biotechnology, 926-68071) or IRDye 800CW antiMouse IgG (Licor Biotechnology, 926-32210) at a 1:8,000 dilution for 1 hour at room temperature. Membranes were washed 3 times with PBS-T for 5 minutes, followed by a rinse in PBS, then imaged using Odyssey CLx Infrared Imaging System (Licor Biotechnology, Lincoln, NE).

\section{$A \beta 42$ and apoE ELISA}

To quantify Aß42 and apoE uptake, cells were treated, washed with PBS 3 times, then lysed in RIPA buffer (sc-24948 Sigma-Aldrich, St. Louis, MO, USA) supplemented with protease inhibitor cocktail, and phosphatase inhibitor cocktail 2 and 3 (sc-24948 Sigma-Aldrich, St. Louis, MO, USA). Total Aß42 was measured via ELISA (Thermo Fisher, KHB3544), total apoE was quantified via ELISA (Abcam ab108813). Uptake was normalized to total mg of protein per sample measured via Bio-Rad DC protein assay kit (5000112 Bio-Rad Laboratories, Hercules, CA, USA).

\section{Confocal Microscopy}


Cells were plated in 8-well chamber slides (Lab-Tek cc2 plates, 154534PK Thermo Scientific). Cells were washed 3 times with PBS then fixed with 4\% paraformaldehyde (Santa Cruz) for 10 minutes at room temperature, washed 3 times with PBS, then permeabilized with $0.1 \%$ Triton X-100 in PBS for 10 minutes at room temperature. Cells were blocked with 10\% Goat Serum (50062Z Thermo Scientific) for one hour then incubated with goat anti-PGRMC1 (Abcam ab48012) 1:200 in PBST +1\% goat serum overnight, washed 3 times with PBST, then incubated with 1:200 donkey anti-goat Alexa488 secondary antibody (A11055 Invitrogen) in PBST for 1 hour. Cells were then washed 3 times in PBST and blocked with 10\% goat serum for an hour, then incubated with 1:50 mouse anti-LDLR (Novus NBP1-78159) in PBST $+1 \%$ goat serum overnight, washed 3 times with PBST, then incubated with 1:200 goat anti-mouse Cy3 secondary antibody (A10521 Invitrogen) in PBST for 1 hour. Cells were washed 3 times with PBST and blocked with $10 \%$ goat serum for an hour, then incubated with rabbit anti-TMEM97 primary antibody (Novus NBP130436) 1:200 in PBST +1\% BSA overnight, washed 3 times with PBST, then incubated with goat anti-rabbit Alexa568 secondary antibody (A-11011 Invitrogen) 1:200 in PBST for an hour. Cells were washed 3 times in PBST, once in PBS, then mounted in ProLong Glass antifade mounting media (Thermo Fisher, P36980). Images were acquired at 40X magnification on a Leica STED 8X Super-resolution Confocal Microscope.

\section{Proximity Ligation Assays}

For the Proximity Ligation Assay, the Duolink In Situ PLA Far Red kit was followed according to manufacturer instructions (Sigma DUO92105).

\section{Sigma-2 receptor saturation binding assay}

For culturing primary cortical neurons, cortical cell suspensions were plated onto poly L-lysine (PLL)-coated T-75 flasks at $4 \times 10^{6}$ cells per flask and cultured in neurobasal medium supplemented with B27 (1x), 100 units $/ \mathrm{ml}$ penicillin, and $100 \mu \mathrm{g} / \mathrm{ml}$ streptomycin. The cell culture medium was partially replaced every 7 days. 2 week-old neurons were harvested by scraping and centrifugation at $2500 \times \mathrm{g}$ for $20 \mathrm{~min}$ at $4^{\circ} \mathrm{C}$. Cell pellets were frozen at $-80^{\circ} \mathrm{C}$ until use. 
For cell membrane preparation, the cell pellets were re-suspended in $10 \mathrm{~mL}$ ice-cold Phosphate-Buffered Saline (PBS), and homogenized using Wheaton overhead stirrer (120 Vac Overhead Stirrer, Millville, NJ) at the speed of 2 for $30 \mathrm{sec}$. Cell homogenates were then centrifuged at $31,000 \times \mathrm{g}$ for $20 \mathrm{~min}$ at $4^{\circ} \mathrm{C}$. The pellets were re-suspended in $1 \mathrm{~mL}$ ice-cold PBS and stored at $-80^{\circ} \mathrm{C}$ freezer.

For saturation binding assays, cell membranes were incubated with [125]]RHM-4 (0.02 - $9 \mathrm{nM})$ for 90 min at room temperature. After incubation, the bound ligands were filtrated and collected on glass fiber papers (Whatman grade 934-AH, GE Healthcare, Pittsburgh, PA) with a M-24 Brandel filtration system (Brandel, Gaithersburg, MD), and counted with a Wizard2 Automatic Gamma Counter 2470. Nonspecific binding was determined in the presence of $10 \mu \mathrm{M}$ DTG. The $\mathrm{K}_{d}$ and $\mathrm{B}_{\max }$ values were calculated by a nonlinear regression analysis using GraphPad Prism version 6 (GraphPad, La Jolla, CA). Protein concentrations were determined by Lowry method. 


\section{LIST OF ABBREVIATIONS}

A $\beta 42$ - amyloid beta 1-42

$A D$ - Alzheimer's Disease

APP - amyloid precursor protein

apoE - apolipoprotein E

CNS - central nervous system

DKO - double knockout

DMPC - dimyristoyl-phosphatidylcholine

fA $\beta 42-A \beta 42$ fibrils

HFIP - hexafluoroisopropanol

LDL - low density lipoprotein

LDLR - Low Density Lipoprotein Receptor

LPDS - lipoprotein depleted serum

LRP - LDLR-related protein

$\mathrm{mA} \beta 42$ - $\mathrm{A} \beta 42$ monomers

oA $\beta 42$ - A $\beta 42$ oligomers

PBS - phosphate buffered saline

PBS-T - phosphate buffered saline with $0.2 \%$ Tween 20

PGRMC1 - Progesterone Receptor Membrane Component 1

PLL - poly L-lysine

TEM - transmission electron microscopy

TMEM97 - Transmembrane Protein 


\section{DECLARATIONS}

Ethics approval and consent to participate: All human tissue was used in accordance with the University of Pennsylvania IRB protocol.

Consent for publication: Not Applicable

Availability of data and materials: Not Applicable

Competing interests: No competing interests

Funding: Research was supported by the Michael J Fox Foundation and NIH NIDA T32 Fellowship

Authors' contributions: AR performed and analyzed uptake experiments in HeLa cells and primary rat neurons, ELISA analysis, confocal microscopy experiments, and manuscript preparation. ZL performed and analyzed TEM experiments and A 342 fibril preparations, CZ performed CRISPR knockout of HeLa cell lines and A 342 microscopy on human tissues, CW performed and analyzed radioligand binding experiments, VL and JT were responsible for tissue sample acquisition, analysis, and pathology, RHM was responsible for experimental organization and rationale, data analysis, organization, and manuscript preparation.

All authors read and approved the final manuscript.

Acknowledgements: Not applicable 


\section{REFERENCES}

1. Bowen WD (2000) Sigma receptors: Recent advances and new clinical potentials. Pharm Acta Helv 74:211-8.

2. Mach RH, Zeng C and Hawkins WG (2013) The sigma2 receptor: a novel protein for the imaging and treatment of cancer. J Med Chem 56:7137-60. doi: 10.1021/jm301545c

3. Walker JM, Bowen WD, Walker FO, Matsumoto RR, De Costa B and Rice KC (1990) Sigma receptors: Biology and function. Pharmacol Rev 42:355-402.

4. Martin WR, Eades CG, Thompson JA, Huppler RE and Gilbert PE (1976) The effects of morphine- and nalorphine- like drugs in the nondependent and morphine-dependent chronic spinal dog. $\mathrm{J}$ Pharmacol Exp Ther 197:517-32.

5. Leonard BE (2004) Sigma receptors and sigma ligands: background to a pharmacological enigma. Pharmacopsychiatry 37 Suppl 3:S166-70. doi: 10.1055/s-2004-832674

6. Izzo NJ, Staniszewski A, To L, Fa M, Teich AF, Saeed F, Wostein H, Walko T, 3rd, Vaswani A, Wardius M, Syed Z, Ravenscroft J, Mozzoni K, Silky C, Rehak C, Yurko R, Finn P, Look G, Rishton G, Safferstein H, Miller M, Johanson C, Stopa E, Windisch M, Hutter-Paier B, Shamloo M, Arancio O, LeVine H, 3rd and Catalano SM (2014) Alzheimer's therapeutics targeting amyloid beta 1-42 oligomers I: Abeta 42 oligomer binding to specific neuronal receptors is displaced by drug candidates that improve cognitive deficits. PLoS One 9:e111898. doi: 10.1371/journal.pone.0111898

7. Izzo NJ, Xu J, Zeng C, Kirk MJ, Mozzoni K, Silky C, Rehak C, Yurko R, Look G, Rishton G, Safferstein H, Cruchaga C, Goate A, Cahill MA, Arancio O, Mach RH, Craven R, Head E, LeVine H, 3rd, Spires-Jones TL and Catalano SM (2014) Alzheimer's therapeutics targeting amyloid beta 1-42 oligomers II: Sigma-2/PGRMC1 receptors mediate Abeta 42 oligomer binding and synaptotoxicity. PLoS One 9:e111899. doi: 10.1371/journal.pone.0111899

8. Riad A, Zeng C, Weng CC, Winters H, Xu K, Makvandi M, Metz T, Carlin S and Mach RH (2018) Sigma-2 Receptor/TMEM97 and PGRMC-1 Increase the Rate of Internalization of LDL by LDL Receptor through the Formation of a Ternary Complex. Sci Rep 8:16845. doi: 10.1038/s41598-018-35430-3 
9. Butterfield DA (2002) Amyloid beta-peptide (1-42)-induced oxidative stress and neurotoxicity: implications for neurodegeneration in Alzheimer's disease brain. A review. Free Radic Res 36:1307-13. doi: $10.1080 / 1071576021000049890$

10. Findeis MA (2007) The role of amyloid beta peptide 42 in Alzheimer's disease. Pharmacol Ther 116:266-86. doi: 10.1016/j.pharmthera.2007.06.006

11. Yankner BA, Dawes LR, Fisher S, Villa-Komaroff L, Oster-Granite ML and Neve RL (1989) Neurotoxicity of a fragment of the amyloid precursor associated with Alzheimer's disease. Science 245:417-20. doi: 10.1126/science.2474201

12. Dahlgren KN, Manelli AM, Stine WB, Jr., Baker LK, Krafft GA and LaDu MJ (2002) Oligomeric and fibrillar species of amyloid-beta peptides differentially affect neuronal viability. J Biol Chem 277:32046-53. doi: 10.1074/jbc.M201750200

13. Masters CL, Simms G, Weinman NA, Multhaup G, McDonald BL and Beyreuther K (1985) Amyloid plaque core protein in Alzheimer disease and Down syndrome. Proc Natl Acad Sci U S A 82:4245-9. doi: 10.1073/pnas.82.12.4245

14. Cataldo AM, Petanceska S, Terio NB, Peterhoff CM, Durham R, Mercken M, Mehta PD, Buxbaum J, Haroutunian V and Nixon RA (2004) Abeta localization in abnormal endosomes: association with earliest Abeta elevations in AD and Down syndrome. Neurobiol Aging 25:1263-72. doi:

10.1016/j.neurobiolaging.2004.02.027

15. D'Andrea MR, Nagele RG, Wang HY, Peterson PA and Lee DH (2001) Evidence that neurones accumulating amyloid can undergo lysis to form amyloid plaques in Alzheimer's disease. Histopathology 38:120-34. doi: 10.1046/j.1365-2559.2001.01082.x

16. Gouras GK, Tsai J, Naslund J, Vincent B, Edgar M, Checler F, Greenfield JP, Haroutunian V, Buxbaum JD, Xu H, Greengard P and Relkin NR (2000) Intraneuronal Abeta42 accumulation in human brain. Am J Pathol 156:15-20. doi: 10.1016/s0002-9440(10)64700-1

17. McLean CA, Cherny RA, Fraser FW, Fuller SJ, Smith MJ, Beyreuther K, Bush Al and Masters CL (1999) Soluble pool of Abeta amyloid as a determinant of severity of neurodegeneration in Alzheimer's disease. Ann Neurol 46:860-6. doi: 10.1002/1531-8249(199912)46:6<860::aid-ana8>3.0.co;2-m 
18. Friedrich RP, Tepper K, Ronicke R, Soom M, Westermann M, Reymann K, Kaether C and Fandrich M (2010) Mechanism of amyloid plaque formation suggests an intracellular basis of Abeta pathogenicity. Proc Natl Acad Sci U S A 107:1942-7. doi: 10.1073/pnas.0904532106

19. Hu X, Crick SL, Bu G, Frieden C, Pappu RV and Lee JM (2009) Amyloid seeds formed by cellular uptake, concentration, and aggregation of the amyloid-beta peptide. Proc Natl Acad Sci U S A 106:20324-9. doi: 10.1073/pnas.0911281106

20. Gouras GK, Tampellini D, Takahashi RH and Capetillo-Zarate E (2010) Intraneuronal betaamyloid accumulation and synapse pathology in Alzheimer's disease. Acta Neuropathol 119:523-41. doi: $10.1007 / \mathrm{s} 00401-010-0679-9$

21. Domert J, Rao SB, Agholme L, Brorsson AC, Marcusson J, Hallbeck M and Nath S (2014) Spreading of amyloid-beta peptides via neuritic cell-to-cell transfer is dependent on insufficient cellular clearance. Neurobiol Dis 65:82-92. doi: 10.1016/j.nbd.2013.12.019

22. Nath S, Agholme L, Kurudenkandy FR, Granseth B, Marcusson J and Hallbeck M (2012)

Spreading of neurodegenerative pathology via neuron-to-neuron transmission of beta-amyloid. J Neurosci 32:8767-77. doi: 10.1523/JNEUROSCI.0615-12.2012

23. Rajendran L, Honsho M, Zahn TR, Keller P, Geiger KD, Verkade P and Simons K (2006) Alzheimer's disease beta-amyloid peptides are released in association with exosomes. Proc Natl Acad Sci U S A 103:11172-7. doi: 10.1073/pnas.0603838103

24. Sardar Sinha M, Ansell-Schultz A, Civitelli L, Hildesjo C, Larsson M, Lannfelt L, Ingelsson M and Hallbeck M (2018) Alzheimer's disease pathology propagation by exosomes containing toxic amyloid-beta oligomers. Acta Neuropathol 136:41-56. doi: 10.1007/s00401-018-1868-1

25. Wei W, Nguyen LN, Kessels HW, Hagiwara H, Sisodia S and Malinow R (2010) Amyloid beta from axons and dendrites reduces local spine number and plasticity. Nat Neurosci 13:190-6. doi: $10.1038 / \mathrm{nn} .2476$

26. Mahley RW and Rall SC, Jr. (2000) Apolipoprotein E: far more than a lipid transport protein. Annu Rev Genomics Hum Genet 1:507-37. doi: 10.1146/annurev.genom.1.1.507

27. Bu G (2009) Apolipoprotein E and its receptors in Alzheimer's disease: pathways, pathogenesis and therapy. Nat Rev Neurosci 10:333-44. doi: 10.1038/nrn2620 
28. Verghese PB, Castellano JM and Holtzman DM (2011) Apolipoprotein E in Alzheimer's disease and other neurological disorders. Lancet Neurol 10:241-52. doi: 10.1016/S1474-4422(10)70325-2 29. Wisniewski T and Frangione B (1992) Apolipoprotein E: a pathological chaperone protein in patients with cerebral and systemic amyloid. Neurosci Lett 135:235-8. doi: 10.1016/0304-3940(92)90444-

C

30. Kuipers BJ and Gruppen H (2007) Prediction of molar extinction coefficients of proteins and peptides using UV absorption of the constituent amino acids at $214 \mathrm{~nm}$ to enable quantitative reverse phase high-performance liquid chromatography-mass spectrometry analysis. J Agric Food Chem 55:5445-51. doi: 10.1021/jf070337|

31. Stine WB, Jungbauer L, Yu C and LaDu MJ (2011) Preparing synthetic Abeta in different aggregation states. Methods Mol Biol 670:13-32. doi: 10.1007/978-1-60761-744-0_2

32. Xiao Y, Ma B, McElheny D, Parthasarathy S, Long F, Hoshi M, Nussinov R and Ishii Y (2015) Abeta(1-42) fibril structure illuminates self-recognition and replication of amyloid in Alzheimer's disease. Nat Struct Mol Biol 22:499-505. doi: 10.1038/nsmb.2991

33. Zeng C, Weng CC, Schneider ME, Jr., Puentes L, Riad A, Xu K, Makvandi M, Jin L, Hawkins WG and Mach RH (2019) TMEM97 and PGRMC1 do not mediate sigma-2 ligand-induced cell death. Cell Death Discov 5:58. doi: 10.1038/s41420-019-0141-2

34. Hartley DM, Walsh DM, Ye CP, Diehl T, Vasquez S, Vassilev PM, Teplow DB and Selkoe DJ (1999) Protofibrillar intermediates of amyloid beta-protein induce acute electrophysiological changes and progressive neurotoxicity in cortical neurons. J Neurosci 19:8876-84.

35. Lambert MP, Barlow AK, Chromy BA, Edwards C, Freed R, Liosatos M, Morgan TE, Rozovsky I, Trommer B, Viola KL, Wals P, Zhang C, Finch CE, Krafft GA and Klein WL (1998) Diffusible, nonfibrillar ligands derived from Abeta1-42 are potent central nervous system neurotoxins. Proc Natl Acad Sci U S A 95:6448-53. doi: 10.1073/pnas.95.11.6448

36. Liu CC, Liu CC, Kanekiyo T, Xu H and Bu G (2013) Apolipoprotein E and Alzheimer disease: risk, mechanisms and therapy. Nat Rev Neurol 9:106-18. doi: 10.1038/nrneurol.2012.263

37. Long JM and Holtzman DM (2019) Alzheimer Disease: An Update on Pathobiology and Treatment Strategies. Cell 179:312-339. doi: 10.1016/j.cell.2019.09.001 
38. Strittmatter WJ, Saunders AM, Goedert M, Weisgraber KH, Dong LM, Jakes R, Huang DY, Pericak-Vance M, Schmechel D and Roses AD (1994) Isoform-specific interactions of apolipoprotein E with microtubule-associated protein tau: implications for Alzheimer disease. Proc Natl Acad Sci U S A 91:11183-6. doi: 10.1073/pnas.91.23.11183

39. Gylys KH, Fein JA, Tan AM and Cole GM (2003) Apolipoprotein E enhances uptake of soluble but not aggregated amyloid-beta protein into synaptic terminals. J Neurochem 84:1442-51. doi:

10.1046/j.1471-4159.2003.01643.x

40. Kane MD, Lipinski WJ, Callahan MJ, Bian F, Durham RA, Schwarz RD, Roher AE and Walker LC (2000) Evidence for seeding of beta -amyloid by intracerebral infusion of Alzheimer brain extracts in beta -amyloid precursor protein-transgenic mice. J Neurosci 20:3606-11.

41. Hou C, Tu Z, Mach R, Kung HF and Kung MP (2006) Characterization of a novel iodinated sigma-2 receptor ligand as a cell proliferation marker. Nucl Med Biol 33:203-9. doi:

10.1016/j.nucmedbio.2005.10.001

42. $\mathrm{Xu} \mathrm{J,} \mathrm{Tu} \mathrm{Z,} \mathrm{Jones} \mathrm{LA,} \mathrm{Vangveravong} \mathrm{S,} \mathrm{Wheeler} \mathrm{KT} \mathrm{and} \mathrm{Mach} \mathrm{RH} \mathrm{(2005)} \mathrm{[3H]N-[4-(3,4-dihydro-}$ 6,7-dimethoxyisoquinolin-2(1H)-yl)butyl]-2-methoxy-5-methyl benzamide: a novel sigma-2 receptor probe. Eur J Pharmacol 525:8-17. doi: 10.1016/j.ejphar.2005.09.063

43. Brettschneider J, Del Tredici K, Lee VM and Trojanowski JQ (2015) Spreading of pathology in neurodegenerative diseases: a focus on human studies. Nat Rev Neurosci 16:109-20. doi:

$10.1038 / \mathrm{nrn} 3887$

44. Robinson JL, Lee EB, Xie SX, Rennert L, Suh E, Bredenberg C, Caswell C, Van Deerlin VM, Yan N, Yousef A, Hurtig HI, Siderowf A, Grossman M, McMillan CT, Miller B, Duda JE, Irwin DJ, Wolk D, Elman L, McCluskey L, Chen-Plotkin A, Weintraub D, Arnold SE, Brettschneider J, Lee VM and Trojanowski JQ (2018) Neurodegenerative disease concomitant proteinopathies are prevalent, agerelated and APOE4-associated. Brain 141:2181-2193. doi: 10.1093/brain/awy146

45. Toledo JB, Van Deerlin VM, Lee EB, Suh E, Baek Y, Robinson JL, Xie SX, McBride J, Wood EM, Schuck T, Irwin DJ, Gross RG, Hurtig H, McCluskey L, Elman L, Karlawish J, Schellenberg G, ChenPlotkin A, Wolk D, Grossman M, Arnold SE, Shaw LM, Lee VM and Trojanowski JQ (2014) A platform for 
discovery: The University of Pennsylvania Integrated Neurodegenerative Disease Biobank. Alzheimers Dement 10:477-484 e1. doi: 10.1016/j.jalz.2013.06.003

46. Innerarity TL, Pitas RE and Mahley RW (1986) Lipoprotein-receptor interactions. Methods Enzymol 129:542-65. doi: 10.1016/0076-6879(86)29091-6 


\section{Figures}

\section{Manuscript title:}

The Sigma-2 Receptor/TMEM97, PGRMC1, and LDL Receptor complex are responsible for the cellular uptake of $A \beta 42$ and its protein aggregates

\section{Authors:}

Aladdin Riad, ${ }^{1}$ Zsofia Lengyel-Zhand,${ }^{1}$ Chenbo Zeng, ${ }^{1}$ Chi-Chang Weng, ${ }^{1}$ Virginia M.-Y. Lee, ${ }^{2}$ and John Q. Trojanowski ${ }^{2}$ and Robert H. Mach ${ }^{1 *}$

1Department of Radiology, University of Pennsylvania, Philadelphia, PA, USA, and ${ }^{2}$ Center for Neurodegenerative Disease Research, Pathology and Laboratory Medicine, University of Pennsylvania, Philadelphia, PA, USA 
A

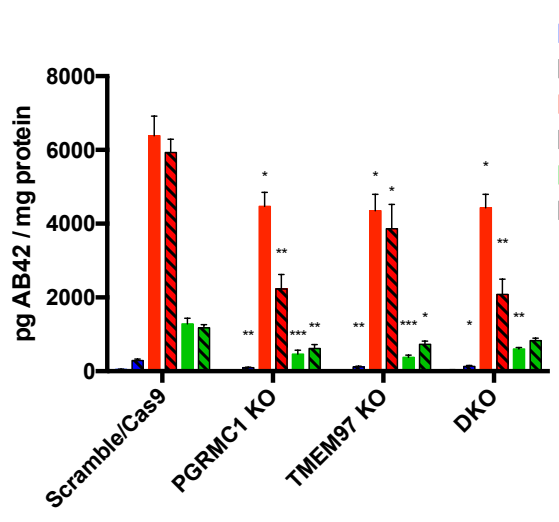

C

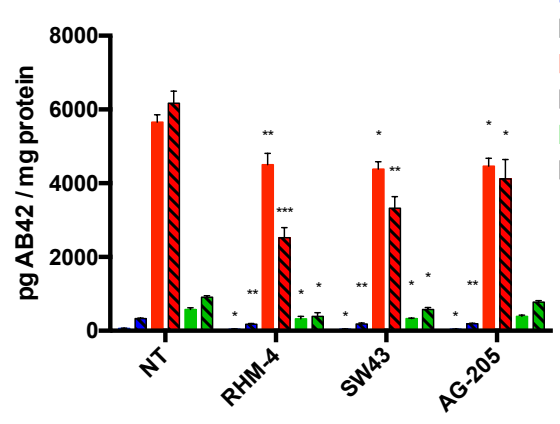

- Monomers B

a Monomers / apoE3

Oligomers

Oligomers / apoE3

Fibrils

Fibrils / apoE3
B

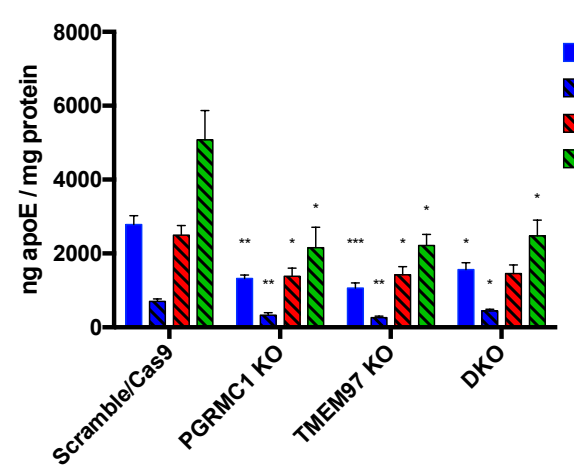

Monomers

Monomers / apoE3

Oligomers

Oligomers / apoE3

Fibrils

Nibrils/apoE3

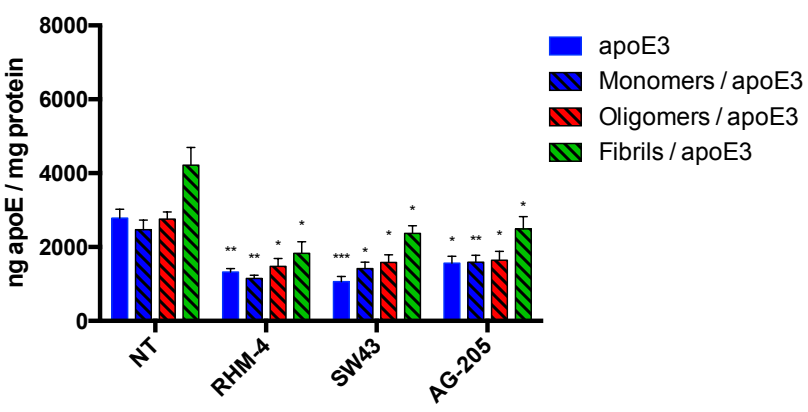

Figure 1. Disruption of the TMEM97/PGRMC1/LDLR complex reduces cell associated A 342 and apoE levels in HeLa cells. Cells were treated with $1000 \mathrm{nM} \mathrm{A \beta 42} \mathrm{monomers,} \mathrm{oligomers,}$ or fibrils in the presence or absence of $250 \mathrm{nM}$ apoE for 24 hours at $37^{\circ} \mathrm{C}$. (A-B) Knockout cell lines compared to control cells (Scramble/Cas9) and cell associated (A) $A \beta 42$ and (B) apoE was quantified. (C-D) Scramble/Cas9 cells treated with either 500nM RHM-4, SW43, or AG-205 were compared to no drug treated Scramble/Cas9 cells (NT) and cell associated (C) $A \beta 42$ and (D) apoE was quantified. Cell associated $A \beta 42$ and apoE was determined via ELISA of cell lysates normalized to total cell protein. Data represents mean $\pm \operatorname{SEM}(n=3) ;{ }^{*}, p$ $<0.05 ;{ }^{* *}, p<0.01 ;{ }^{* * *}, p<0.001 ;{ }^{* * *} p<0.0001$; one way ANOVA for each treatment compared to control. 
A

Scramble/Cas9

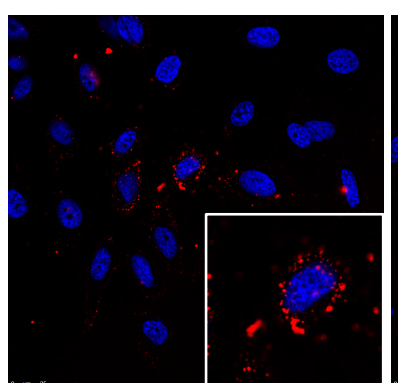

$30 \min$

$60 \min$
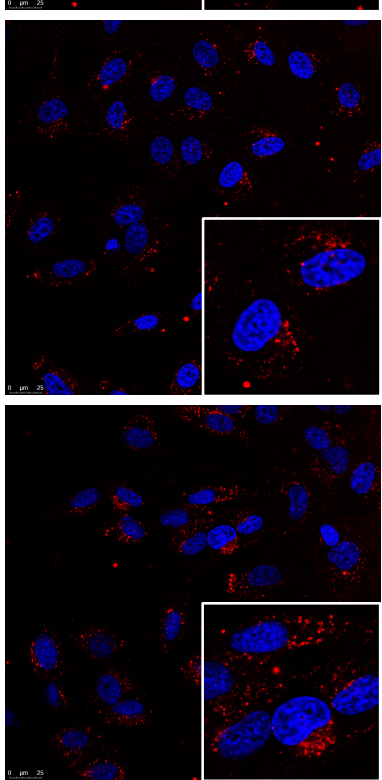

PGRMC1 KO
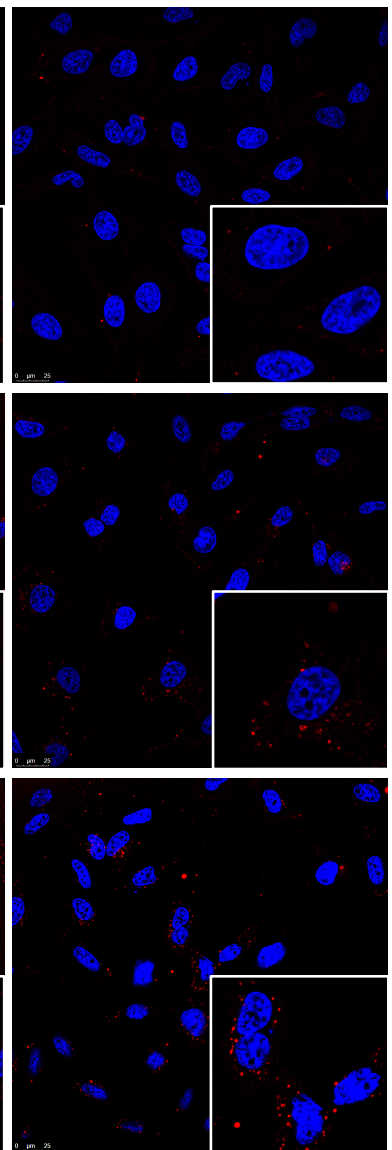

TMEM97 KO
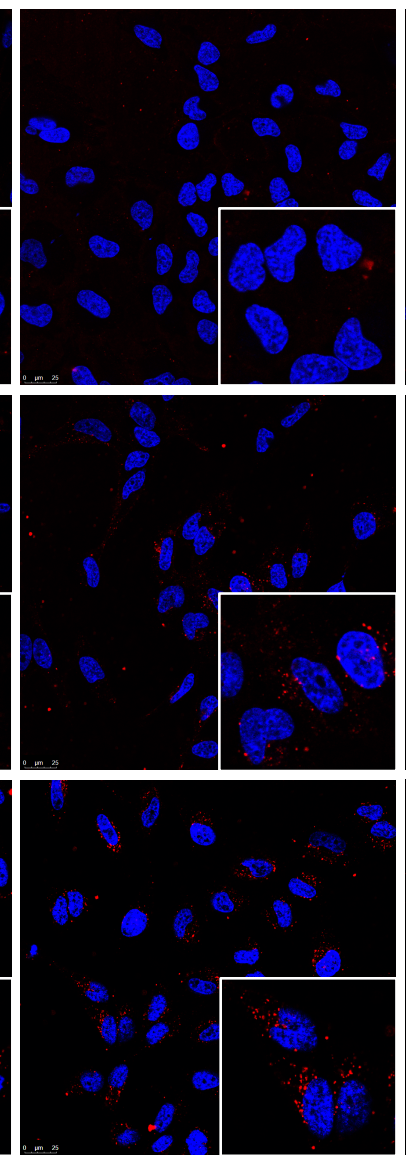

B
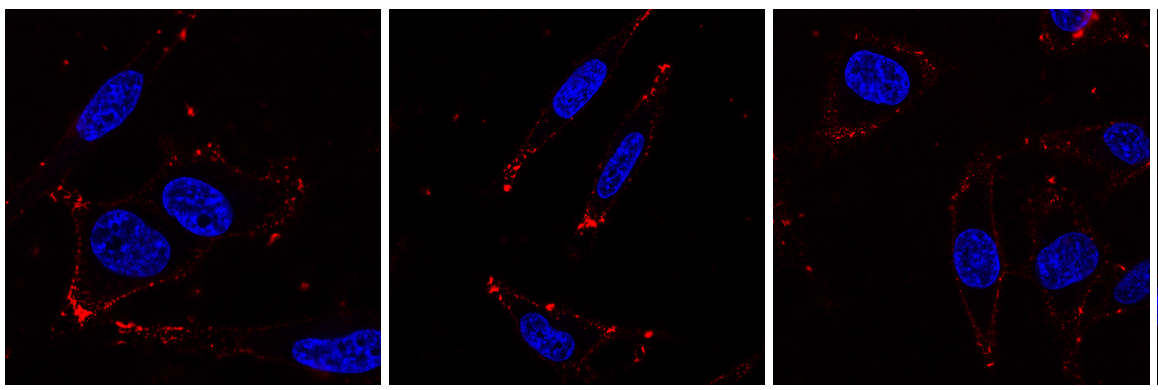

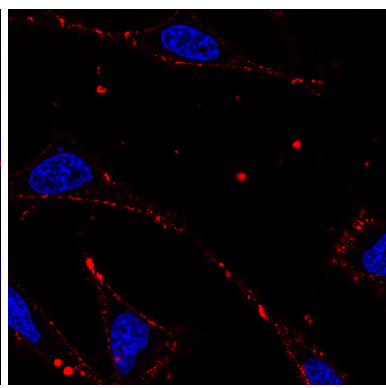

Figure 2. Confocal images of HeLa cell lines treated with fluorescent $A \beta 42$ oligomers and fibrils. (A) Fluorescent $A \beta 42$ oligomers treated at $10 \mathrm{~min}, 30 \mathrm{~min}$, and $60 \mathrm{~min}$. Inserts are expanded cells of interest. (B) Fluorescent $A \beta 42$ treated for 60 minutes. Cells were stained with Hoechst (blue) prior to treatment with fluorescent $A \beta 42$ (red) for indicated times, washed, and imaged immediately. 

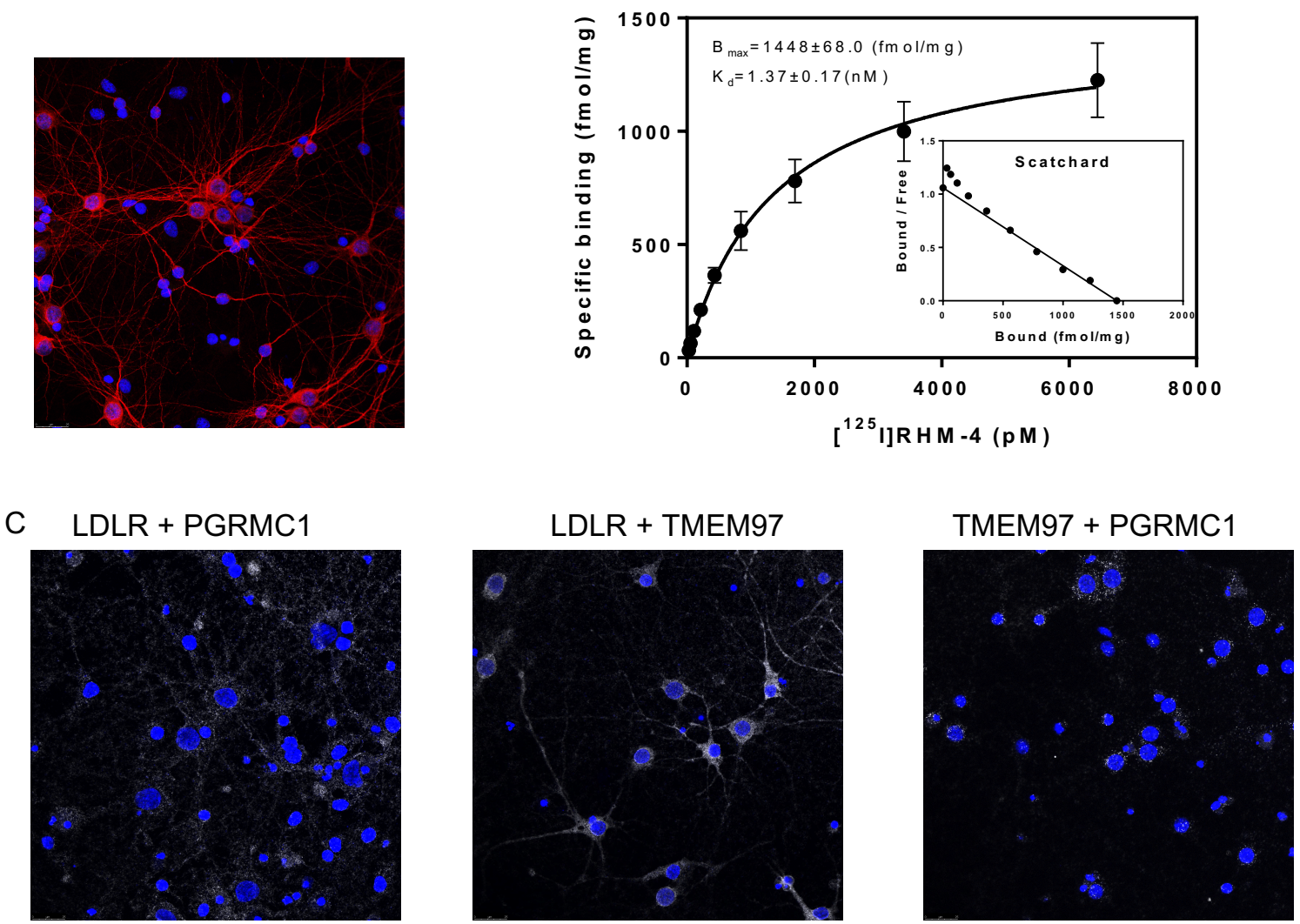

Figure 3. Characterization of Primary Neurons. (A) Confocal microscopy images of primary neuron MAP2 staining (red) indicates primary neurons are mature and display healthy neuronal structure. (B) Determination of sigma-2 receptor densities in rat cortical neurons by receptor binding assay using [ ${ }^{125}$ ] RHM-4. Inset is a scatchard plot. $K_{d}$ and $B_{\max }$ were calculated by a nonlinear regression analysis using GraphPad Prism software. Data represent mean \pm SD of at least 3 experiments performed in duplicate. (C) Pairwise Proximity Ligation Assay on DIV 21 primary rat cortical neurons. Confocal microscopy images of fluorescent signals (white) indicate an interaction between LDLR and PGRMC1, LDLR and TMEM97, and TMEM97 and PGRMC1; indicating the presence of a trimeric complex. 

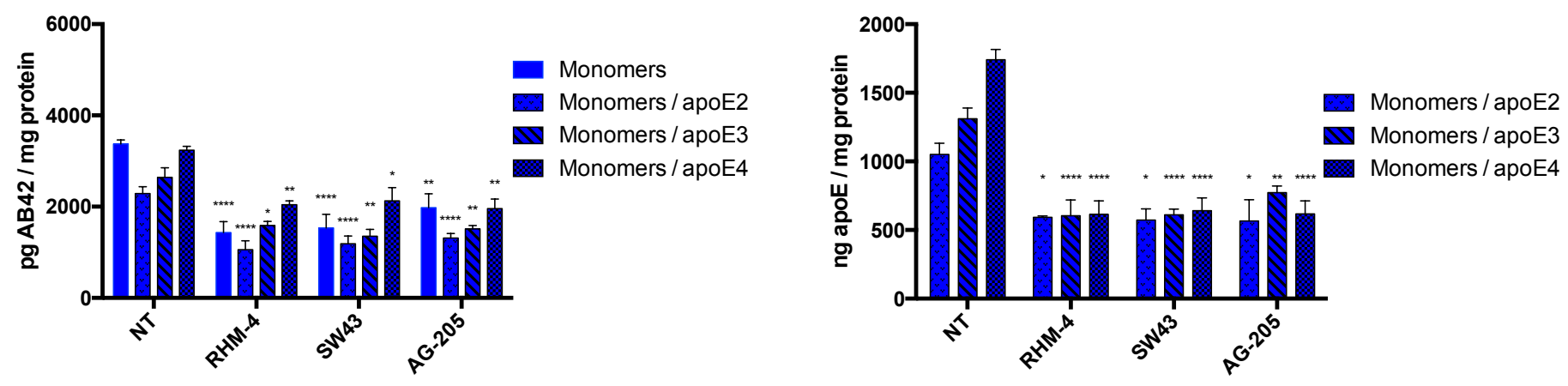

B

$\mathrm{E}$
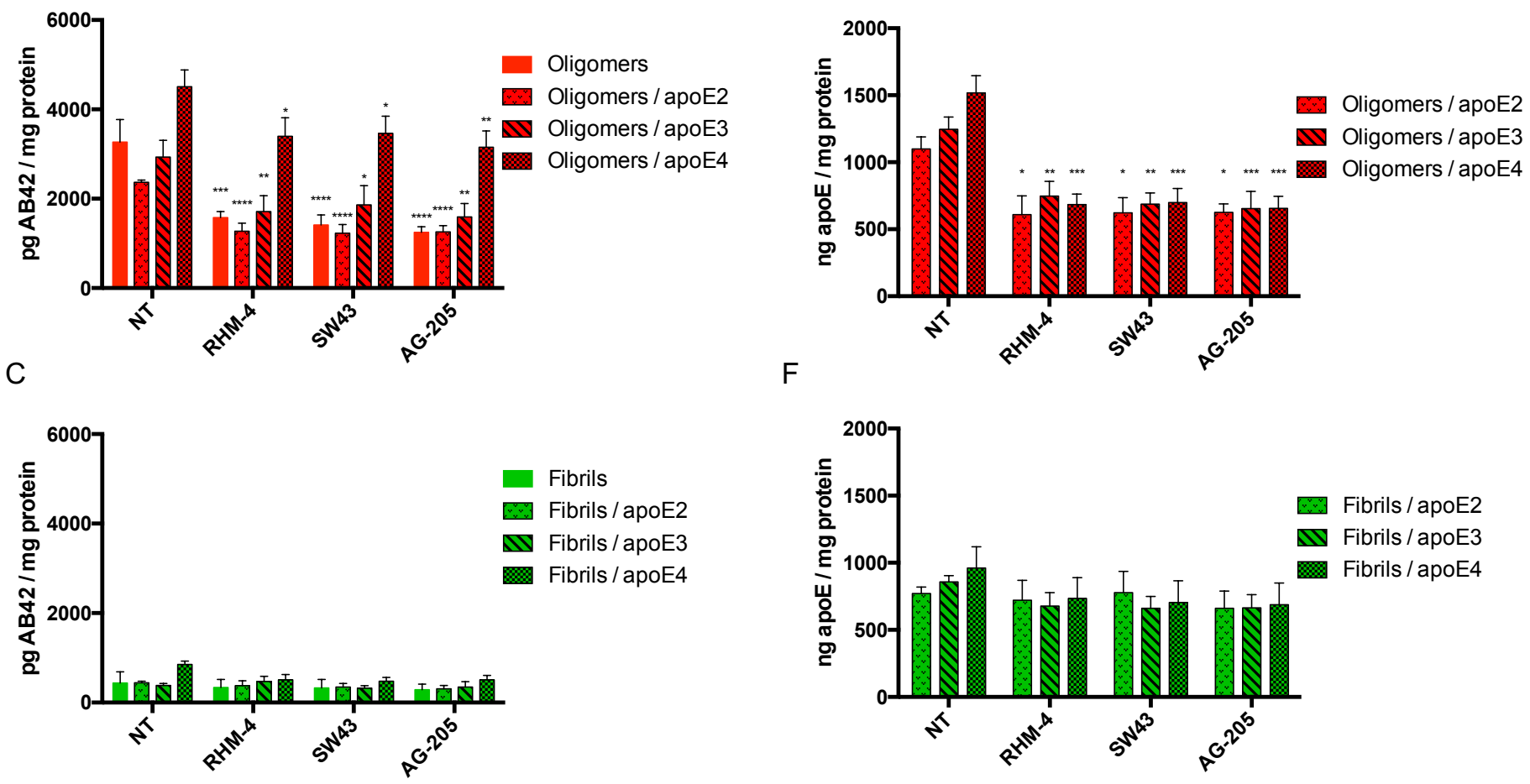

Fibrils

Fibrils / apoE2

NV Fibrils/apoE3

— Fibrils/apoE4

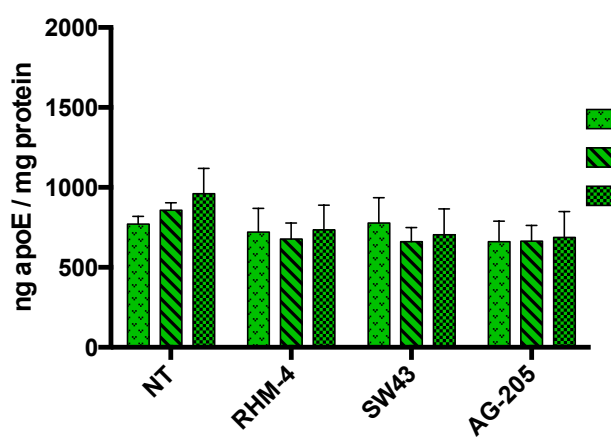

Fibrils / apoE2

NV Fibrils / apoE3

Fibrils / apoE4

Figure 4. Treatment of primary rat cortical neurons (DIV21) with various sigma 2 ligands reduces the uptake of $A \beta 42$ monomers and oligomers in the presence and absence of apoE. Primary neurons were treated with 500nM RHM-4, SW43, or AG-205 and uptake of Aß42 monomers, oligomers, and fibrils with or without apoE2, apoE3 or apoE4 was quantified. Uptake was compared to no compound treated controls (NT). Drug treatment resulted in a reduction of $A \beta 42(A)$ monomers and $(B)$ oligomers but not (C) fibrils when treated alone or in a complex with any apoE isoforms. (D-F) Quantification of apoE was assessed for these treatment groups. Cell associated $A \beta 42$ and apoE was determined via ELISA of cell lysates normalized to total cell protein. Data represents mean \pm SEM $(n=4) ;{ }^{*}, p<0.05 ;{ }^{* *}, p<0.01 ;{ }^{* * *}, p<0.001 ;{ }^{* * * *} p<0.0001$; one way ANOVA for each treatment compared to control. 


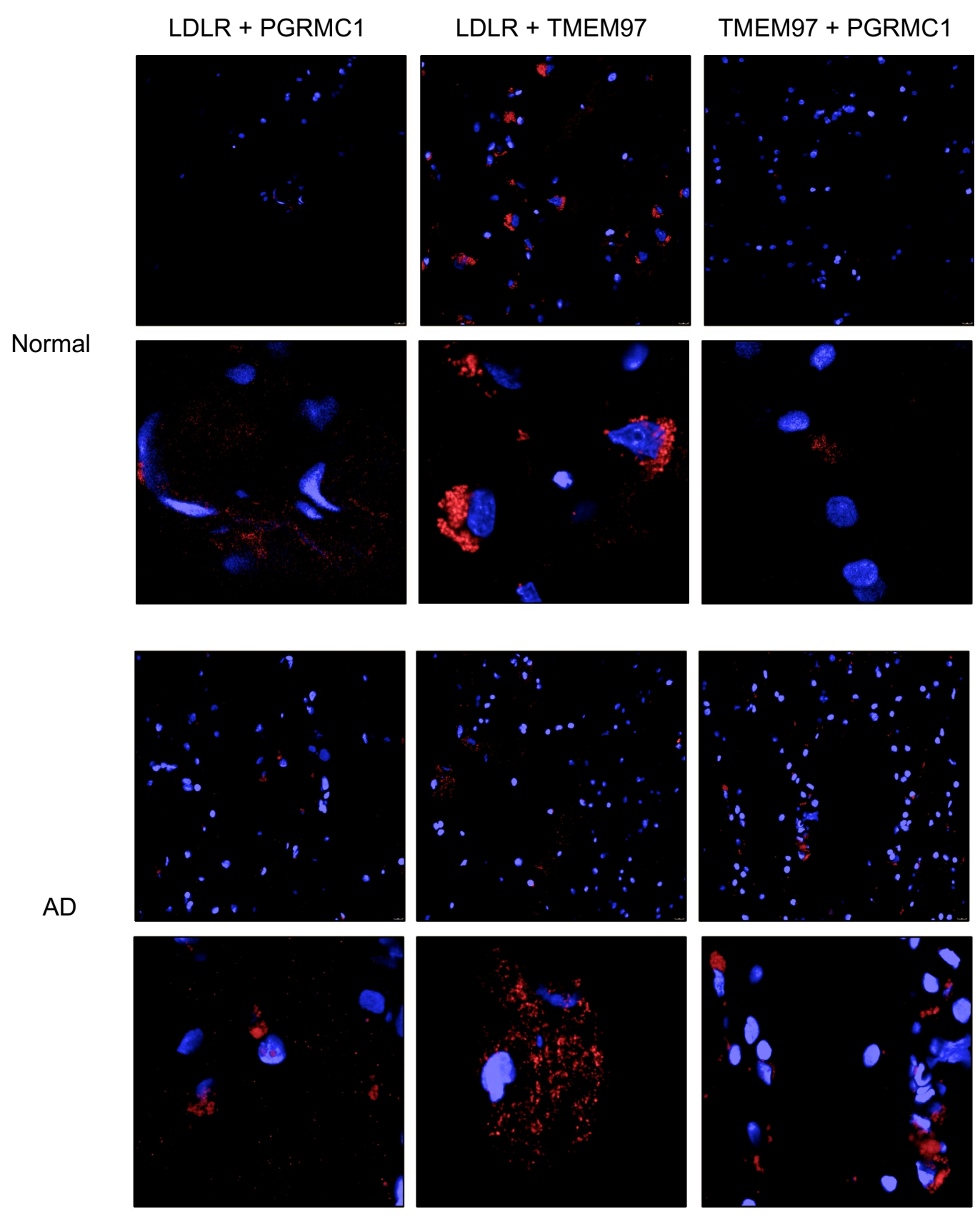

Figure 5. Pairwise Proximity Ligation Assay on normal adult human brain and Alzheimer's Disease human brain. Fluorescent signals (red) indicate an interaction between LDLR and PGRMC1, LDLR and TMEM97, and TMEM97 and PGRMC1; indicating the trimeric complex is intact in normal and diseased human brains. Top 40X magnification, Bottom, expanded field of interest. 